Dalal Ibraheem Ressan

Saturday, December 18, 2010

12:19 AM

Unfiled Notes Page 1 


\title{
Some Results of Feebly Open and Feebly Closed Mappings
}

\section{Dalal Ibraheem Ressan*}

\begin{abstract}
Date of acceptance 6/3/2009
Abstract

The main purpose of this paper is to study feebly open and feebly closed mappings and we proved several results about that by using some concepts of topological feebly open and feebly closed sets, semi open (- closed ) set, gs-(sg-) closed set and composition of mappings.
\end{abstract}

Key words: Feebly open set, feebly closed set, semi open set, semi closed set, feebly open and feebly closed mappings.

\section{Introduction:}

Feebly open and feebly closed mappings are one of the important properties for studying topological spaces. Several results of feebly open and feebly closed mappings occur in the literature, many authors used the concept feebly open and feebly closed sets to study another concepts of topological and gave several results about that .In fact, Maheshwari and U.Tapi [1] introduced the concept of feebly open set,in a topological space $(\mathrm{X}, \mathrm{T}), \mathrm{H}$ set in $\mathrm{X}$ is said to be feebly open if $\mathrm{H} \subset \mathrm{Scl}$ IntH, and accustomed $\mathrm{H}$ is said to be feebly closed if sInt $\mathrm{ClH} \subset \mathrm{H}$. Neubrunn [2] gave an example, let $\mathrm{X}$ and $\mathrm{Y}$ be the set of real numbers with usual topology, let the mapping $\mathrm{F}: \mathrm{X} \rightarrow \mathrm{Y}$ be defined as follows $F(x)=x$ if $x \neq 0$ and $x \neq 1 ; F(0)$ $=1$ and $F(1)=0$. Then $F$ is one- one, feebly continuous and feebly open.S.kolyada,L.Snoha and J.Trofimchuk[3]proved,let $\mathrm{X}$ be a compact Hausdorff space and let $\mathrm{f}$ $\in \mathrm{C}(\mathrm{X})$ be a minimal map, then $\mathrm{f}$ is feebly open, where we write $\mathrm{f}$ $\in \mathrm{C}(\mathrm{X})$, let $(\mathrm{X}, \mathrm{T})$ be adynamical system given by a compact topological space and a continuous map $\mathrm{f}: \mathrm{X} \rightarrow \mathrm{X}$ and adynamical system $(X, T)$ is called minimal if $\mathrm{X}$ is minimal and the map $\mathrm{f}$ itself is minimal.Mahide Kucuk and Idris Zorlutuna [4] them introduce some concepts as a generalization of the concepts of feebly -normality and feebly -regularity[5].A.Vella[6]proved some results concerning a connected compact feebly Hausdorff edge space , where the compact feebly Hausdorff edge space is a main results of [7] and [8]. Ali[9] proved, in a topological space every open set is feebly open set and every closed set is feebly closed set .In this paper we shall study feebly open and feebly closed mappings, we prove several results about that by using another concepts .

Throughout this paper $(\mathrm{X}, \mathrm{T})$ and ( $\mathrm{Y}, \mathrm{V})$ respresent non-empty topological spaces on which no separation axioms are assumed unless stated explicitly and they are simply written as $\mathrm{X}$ and $\mathrm{Y}$ If $\mathrm{F}:(\mathrm{X}, \mathrm{T}) \rightarrow(\mathrm{Y}, \mathrm{V})$ be a mapping , $\mathrm{F}^{-1}(\mathrm{H})$ is the inverse image of for a subset $\mathrm{H}$ of $(\mathrm{X}, \mathrm{T}) \cdot \mathrm{H}^{0}, \mathrm{H}$ and $\mathrm{H}^{\mathrm{c}}$ denote the interior, closure and complement of $\mathrm{H}$ respectively .The operation $\mathrm{O}$ denote the composition of mappings

\section{Preliminaries:}

Asubset $\mathrm{H}$ of a topological space $(\mathrm{X}, \mathrm{T})$ is said to be semi open [10] if there exists an open set $\mathrm{U}$ of $\mathrm{X}$ such that $\mathrm{U} \subset \mathrm{H} \subset \mathrm{Cl}(\mathrm{U})$ and is said semi closed if there exists closed set $U$ such that $\mathrm{U}^{0} \subset \mathrm{H} \subset \mathrm{U}$. The complement of a semi open set is said to be semi closed

Al- Mustansiriyah University-College of Education - Department of Mathematics 
The semi closure [11] and [12] of subset $\mathrm{H}$ of $(\mathrm{X}, \mathrm{T})$, denoted by $\mathrm{sCl}(\mathrm{H})$, briefly, $\mathrm{sCl}(\mathrm{H})$, is defined to be intersection of all semi closed sets containing $\mathrm{H}, \mathrm{sCl}(\mathrm{H})$ is a semi closed set in[11] and [12] the semi interior [12] of $\mathrm{H}$, denoted by $\operatorname{sint}(\mathrm{H})$, is defined by union of all semi open sets contained in $\mathrm{H}$.

Asubset $\mathrm{H}$ of $(\mathrm{X}, \mathrm{T})$ is said to be semi generalized closed (written in short as sg-closed ) in (X,T) [13]if $\mathrm{sCl}(\mathrm{H}) \subset \mathrm{U}$ whenever $\mathrm{H} \subset \mathrm{U}$ and $\mathrm{U}$ is semi open in $(\mathrm{X}, \mathrm{T}), \mathrm{H}$ is said to be generalized semi closed (written as gs -closed) in $(\mathrm{X}, \mathrm{T})$ if $\mathrm{sCl}(\mathrm{H}) \subset \mathrm{U}$ whenever $\mathrm{H} \subset \mathrm{U}$ and $\mathrm{U}$ is open in $(\mathrm{X}, \mathrm{T})$.Also is said to be generalized closed set (written as $\mathrm{g}$-closed )if $\mathrm{Cl}$ (H) $\subset \mathrm{U}$ whenever $\mathrm{H} \subset \mathrm{U}$ and $\mathrm{U}$ is open set and a topological space $(\mathrm{X}, \mathrm{T})$ is said to be $\mathrm{Tb}$ if every gs-closed set is closed.

To a chieve our purpose we mention the following.

\section{Definition 2.1[14]}

A function $\mathrm{F}: \mathrm{X} \rightarrow \mathrm{Y}$ is called feebly closed if the image of each closed set in $\mathrm{X}$ is feebly closed set in Y.

We introduce the definition of feebly open mapping as follows

Definition 2.2

A function $\mathrm{F}: \mathrm{X} \rightarrow \mathrm{Y}$ is called feebly open if the image of each open set in $\mathrm{X}$ is feebly open set in $\mathrm{Y}$.
The following example illustartes above definition .

\section{Example 2.3}

Let $\mathrm{T}=\{\phi,\{\mathrm{a}\},\{\mathrm{a}, \mathrm{b}, \mathrm{c}\}, \mathrm{X}\}$ be a topology on $\mathrm{X}=\{\mathrm{a}, \mathrm{b}, \mathrm{c}, \mathrm{d}\}$ and let $\mathrm{V}=\{\phi,\{\mathrm{p}\}$, $\{q, r\}, Y\}$ be a topology on $Y=\{p, q, r\}$, let $\mathrm{F}: \mathrm{X} \rightarrow \mathrm{Y}$ be defined as follows :

$\mathrm{F}(\mathrm{a})=\mathrm{p}, \mathrm{F}(\mathrm{b})=\mathrm{q}$ and $\mathrm{F}(\mathrm{c})=\mathrm{F}(\mathrm{d})=\mathrm{r}$.

If we take any open set of $X$ say $\{a\}$ , then $F(\{a\})=\{p\}$ which is feebly open set in Y . Similary for other open sets in X.

\section{Definition 2.4 [15]}

Afunction $\mathrm{F}: \mathrm{X} \rightarrow \mathrm{Y}$ is said to be feebly continuous if the inverse image by $\mathrm{F}$ of each open set $\mathrm{V}$ of $\mathrm{Y}$ is feebly open in X.

Theorem 2.5 [9:Proposition 1.3.15]

Let $(X, T)$ be a topological space , $\mathrm{H} \subset \mathrm{X}$, if $\mathrm{H}$ is feebly open then $\mathrm{H}$ is semi open set .

\section{Proposition 2.6}

If $\mathrm{H}$ is an open and $\mathrm{g}$-closed subset of a topological space $(X, T)$, then $H$ is closed set.

Proof:Since $\mathrm{H}$ is open and g-closed, $\bar{H} \subset \mathrm{H} \quad$ but $\mathrm{H} \subset \bar{H} \quad$ always, hence $\bar{H}=\mathrm{H}$, then $\mathrm{H}$ is closed set.

Proposition 2.7 [16]

Let $(\mathrm{X}, \mathrm{T})$ be a topological space, $\mathrm{H} \subset$ $\mathrm{X}$, if $\mathrm{H}$ is feebly open set then $\mathrm{H}^{\mathrm{c}}$ is feebly closed set of X.

From [9] and [13] we obtain the following diagram.

\section{Diagram 2.8}

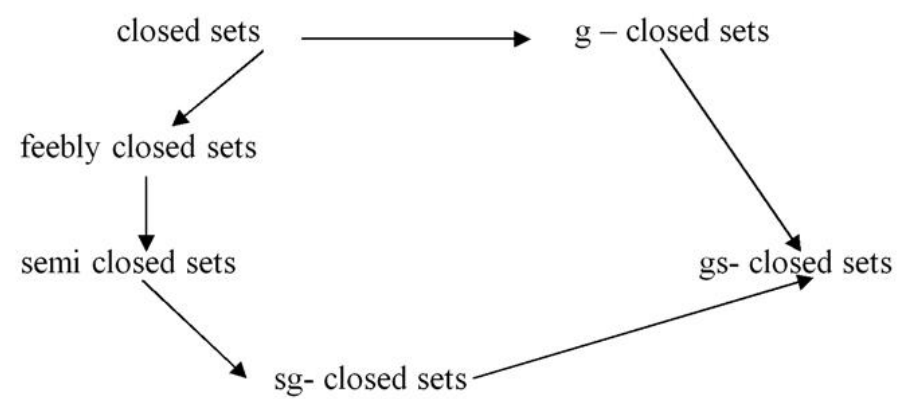

Where $\mathrm{H} \rightarrow U$ represents that $\mathrm{H}$ implies $\mathrm{U}$.

The Main Results:

Theorem 3.1 
Every closed mapping is feebly closed mapping .

Proof:Let $\mathrm{F}: \mathrm{X} \rightarrow \mathrm{Y}$ be a closed mapping, to prove $\mathrm{F}$ is feebly closed , let $\mathrm{H}$ be any closed subset of $\mathrm{X}$. Since $F$ is closed mapping, $F(H)$ is closed in $\mathrm{Y}$.By Diagram $2.8, \mathrm{~F}(\mathrm{H})$ is feebly closed.

Hence $\mathrm{F}$ is feebly closed mapping.

Remark 3.2

The converse of the above theorem is not true always as below .

\section{Example 3.3}

Let $\mathrm{T}=\{\phi, X,\{1\},\{2,3\}\}$ be a topology on $\mathrm{X}=\{1,2,3\}$ and

let $\mathrm{V}=\{\phi, Y,\{\mathrm{a}\},\{\mathrm{a}, \mathrm{c}\}\}$ be a topology on $\mathrm{Y}=\{\mathrm{a}, \mathrm{b}, \mathrm{c}\}$, let $\mathrm{F}: \mathrm{X} \rightarrow \mathrm{Y}$ be defined by: $F(1)=F(2)=F(3)=c$.

It is clearly $\mathrm{F}$ is feebly closed mapping but not closed.since the image of any closed subset of $\mathrm{X}$ is $\{\mathrm{c}\}$ which is not closed but $\{\mathrm{c}\}$ is feebly closed subset of Y.

\section{Theorem 3.4}

Every open mapping is feebly open mapping .

Proof :Let $\mathrm{F}: \mathrm{X} \rightarrow \mathrm{Y}$ be an open mapping, to prove $\mathrm{F}$ is feebly open, let $\mathrm{H}$ be any open subset of $\mathrm{X}$. Since $\mathrm{F}$ is open, $\mathrm{F}(\mathrm{H})$ is open in $\mathrm{Y}, \mathrm{F}(\mathrm{H})$ is feebly open. Hence $\mathrm{F}$ is feebly open mapping .

\section{Remark 3.5}

The converse of the above theorem is not necessarily true,the following example illustrates that.

\section{Example 3.6}

Let $\mathrm{T}=\{\phi, X,\{\mathrm{a}\},\{\mathrm{b}, \mathrm{c}\}\}$ be $\mathrm{a}$ topology on $X=\{a, b, c\}$ and

let $\mathrm{V}=\{\phi, \mathrm{Y},\{1\},\{1,2,3\}\}$ be a topology on $\mathrm{Y}=\{1,2,3,4\}$,

let $\mathrm{F}: \mathrm{X} \rightarrow \mathrm{Y}$ be defined by: $\mathrm{F}(\mathrm{a})=\mathrm{F}(\mathrm{b})$ $=1$ and $F(c)=3$.

It is clearly $\mathrm{F}$ is feebly open but not open, since $F(\{a\})=\{1\}$ which is open and feebly open but $\mathrm{F}(\{\mathrm{b}, \mathrm{c}\})=$ $\{1,3\}$ which is feebly open but not open.

\section{Proposition 3.7}

Let $\mathrm{F}: \mathrm{X} \rightarrow \mathrm{Y}$ be a feebly closed mapping then the image of every closed subset of $\mathrm{X}$ is semi closed in $\mathrm{Y}$.

Proof : Let $\mathrm{H}$ be any closed subset of $\mathrm{X}$ and $\mathrm{F}(\mathrm{H})$ is feebly closed inY, then by Diagram $2.8, \mathrm{~F}(\mathrm{H})$ is semi closed in $\mathrm{Y}$. By the same method we can prove the following proposition.

\section{Proposition 3.8}

Let $\mathrm{F}: \mathrm{X} \rightarrow \mathrm{Y}$ be a feebly closed mapping then the image of every closed subset of $\mathrm{X}$ is gs-closed ( resp. $\mathrm{sg}$-closed ) in Y .

By Proposition 2.6 and Diagram2.8, we can prove the following proposition

\section{Proposition 3.9}

Let $\mathrm{F}: \mathrm{X} \rightarrow \mathrm{Y}$ be a mapping if the image of every closed subset of $X$ is open and g- closed in $\mathrm{Y}$, then $\mathrm{F}$ is feebly closed.

\section{Theorem 3.10}

Let $\mathrm{F}: \mathrm{X} \rightarrow \mathrm{Y}$ be a mapping if the image of every closed subset of $\mathrm{X}$ is gs-closed in Yand $\mathrm{Y}$ is $\mathrm{Tb}$ space, then $\mathrm{F}$ is feebly closed.

Proof: Let $\mathrm{H}$ is closed subset of $\mathrm{X}$ and $\mathrm{F}(\mathrm{H})$ is gs-closed in $\mathrm{Y}$, since $\mathrm{Y}$ is $\mathrm{Tb}$ space, $F(H)$ is closed, then $F(H)$ is feebly closed .Thus $\mathrm{F}$ is feebly closed mapping.

By the same method in Proposition 3.7, we can prove the following proposition

\section{Proposition 3.11}

Let $\mathrm{F}: \mathrm{X} \rightarrow \mathrm{Y}$ be a feebly open mapping then the image of every open subset of $\mathrm{X}$ is semi open in $\mathrm{Y}$.

Theorem 3.12

A mapping $\mathrm{F}: \mathrm{X} \rightarrow \mathrm{Y}$ is feebly open if $\mathrm{F}\left(\mathrm{H}^{\circ}\right) \subset(\mathrm{F}(\mathrm{H}))^{\circ}$ for every $\mathrm{H} \subset \mathrm{X}$. Proof:Let $\mathrm{H}$ be any open set in $\mathrm{X}$ so that $\mathrm{H}^{\mathrm{o}}=\mathrm{H}$, then $\mathrm{F}\left(\mathrm{H}^{\mathrm{o}}\right)=\mathrm{F}(\mathrm{H})$. By our hypothesis $\mathrm{F}\left(\mathrm{H}^{\mathrm{o}}\right) \subset(\mathrm{F}(\mathrm{H}))^{\circ}$ , therefore, $\quad \mathrm{F}(\mathrm{H}) \subset(\mathrm{F}(\mathrm{H}))^{\circ}$. $\operatorname{But}(\mathrm{F}(\mathrm{H}))^{\circ} \subset \mathrm{F}(\mathrm{H})$ always .Hence $(\mathrm{F}(\mathrm{H}))^{\circ}=\mathrm{F}(\mathrm{H})$, therefore, $\mathrm{F}(\mathrm{H})$ is open in $\mathrm{X}$, then $\mathrm{F}$ is open, hence by Theorem $3.4, \mathrm{~F}$ is feebly open. 
Theorem 3.13

A mapping $\mathrm{F}: \mathrm{X} \rightarrow \mathrm{Y}$ is feebly closed if $\overline{F(H)} \subset \mathrm{F}(\bar{H})$ for every $\mathrm{H} \subset \mathrm{X}$.

Proof :Let $\mathrm{H}$ be any closed set in $\mathrm{X}$ so that $\quad \bar{H}=\mathrm{H}$. By hypothesis $\overline{F(H)} \subset \mathrm{F}(\bar{H})=\mathrm{F}(\mathrm{H}), \quad$ therefore, $\overline{F(H)} \subset \mathrm{F}(\mathrm{H}) \cdot \operatorname{ButF}(\mathrm{H}) \subset \overline{F(H)}$

always. Hence $\overline{F(H)}=\mathrm{F}(\mathrm{H})$, thus $\mathrm{F}$ $(\mathrm{H})$ is closed,then $\mathrm{F}$ is closed .It follows from Theorem $3.1, \mathrm{~F}$ is feebly closed.

\section{Theorem 3.14}

Let $\{\mathrm{V} \lambda: \lambda \in \wedge\}$ be an arbitrary collection of topologies on a set $\mathrm{Y}$ and $(\mathrm{X}, \mathrm{T})$ any other topological space .If the mapping $\mathrm{F}: \mathrm{X} \rightarrow \mathrm{Y}$ is feebly open for every $\lambda \in \wedge$, then $F$ is feebly open with respect to the intersection topology $\mathrm{V}=\cap\{\mathrm{V} \lambda: \lambda \in \wedge\}$.

Proof : Let $\mathrm{H}$ be any open subset of $\mathrm{X}$ Since $F$ is feebly open, then $F(H)$ is feebly open in $\mathrm{V} \lambda \quad \forall \lambda \in \wedge$ this implies that $\mathrm{F}(\mathrm{H}) \in \cap\{\mathrm{V} \lambda: \lambda \in \wedge\}=\mathrm{V}$ Thus the image of every open set in $\mathrm{X}$ under $\mathrm{F}$ is feebly open in Y.Hence F is feebly open with respect to the intersection topologies .

Remark 3.15

(i)If $\mathrm{F}: \mathrm{X} \rightarrow \mathrm{Y}$ be a feebly open then $\mathrm{F}$ is not necessarily feebly closed.

(ii)The converse of (i) is not ture always, as below.

Example :3.16

Let $(X, T)$ be any topological space and $(\mathrm{Y}, \mathrm{V})$ be the space for which $\mathrm{Y}=$ $\{p, q, r\}$ and $V=\{\phi,\{p\},\{p, r\}, Y\}$, the mapping $\mathrm{F}: \mathrm{X} \rightarrow \mathrm{Y}$

defined by $: \mathrm{F}(\mathrm{x})=\mathrm{P} \quad \forall \mathrm{x} \in \mathrm{X}$.

Then $\mathrm{F}$ is feebly open but not feebly closed since the image of any closed subset of $\mathrm{X}$ is $\{\mathrm{P}\}$ but $\{\mathrm{P}\}$ is not feebly closed set.

Also we define a mapping $\mathrm{G}: \mathrm{X} \rightarrow \mathrm{Y}$ by : $\mathrm{G}(\mathrm{x})=\mathrm{q} \forall \mathrm{x} \in \mathrm{X}$.

Then $G$ is feebly closed but not feebly open since the image of any open subset of $X$ is $\{q\}$ but $\{q\}$ is not feebly open set .

\section{Theorem 3.17}

If $\mathrm{F}: \mathrm{X} \rightarrow \mathrm{Y}$ is a bijective and feebly open mapping, then $\mathrm{F}$ is feebly closed mapping .

Proof: Let $\mathrm{H}$ be any closed in $\mathrm{X}$, to prove $\mathrm{F}(\mathrm{H})$ is feebly closed in $\mathrm{Y}$, we have $\mathrm{H}^{\mathrm{c}}$ is open and $\mathrm{F}$ is feebly open , then $\mathrm{F}\left(\mathrm{H}^{\mathrm{c}}\right)$ is feebly open, by Proposition 2.7, $\left(\mathrm{F}\left(\mathrm{H}^{\mathrm{c}}\right)\right)^{\mathrm{c}}$ is feebly closed Since $\mathrm{F}$ is $1-1$ and onto then $\left(\mathrm{F}\left(\mathrm{H}^{\mathrm{c}}\right)\right)^{\mathrm{c}}=\mathrm{F}(\mathrm{H})$, thus $\mathrm{F}(\mathrm{H})$ is feebly closed in Y.Hence $F$ is feebly closed.

Feebly open and feebly closed of the composition mappings.

Theorem 4.1

Let $\mathrm{F}: \mathrm{X} \rightarrow \mathrm{Y}$ and $\mathrm{G}: \mathrm{Y} \rightarrow \mathrm{Z}$ be a mappings, then Go $F: X \rightarrow Z$ is feebly open if:

(i ) F and $\mathrm{G}$ be an open mappings

( ii ) $\mathrm{F}$ is open and $\mathrm{G}$ is feebly open mappings .

Proof: ( i ) Let $\mathrm{H}$ be any open subset of $\mathrm{X}$, to prove $\mathrm{GoF}(\mathrm{H})$ is feebly open in $Z$. Since $F$ is open, then $F(H)$ is open in $\mathrm{Y}$.

Also we have $\mathrm{G}$ is open , then $\mathrm{G}(\mathrm{F}(\mathrm{H})$ ) is open in $\mathrm{Z}$, therefore, $\mathrm{GoF}(\mathrm{H})$ is feebly open in $Z$. Thus $\mathrm{GoF}$ is feebly open mapping .

(ii) By same method in part (i) .

Theorem 4.2

Let GoF : $\mathrm{X} \rightarrow \mathrm{Z}$ is open and $\mathrm{G}: \mathrm{Y} \rightarrow$ $\mathrm{Z}$ is feebly continuous and injective , then $\mathrm{F}: \mathrm{X} \rightarrow \mathrm{Y}$ is feebly open.

Proof : Let $H$ is open in $X$, to prove $\mathrm{F}(\mathrm{H})$ is feebly open in $\mathrm{Y}$. Since GoF is open, then $\mathrm{GoF}(\mathrm{H})$ is open in $\mathrm{Z}$, also we have $G$ is feebly continuous, then, $\mathrm{G}^{-1}(\mathrm{G}(\mathrm{F}(\mathrm{H})))$ is feebly open in $\mathrm{Y}$ but $\mathrm{G}$ is injective , therefore $\mathrm{G}^{-1}(\mathrm{G}(\mathrm{F}(\mathrm{H})))=$ $\mathrm{F}(\mathrm{H})$ is feebly open in $\mathrm{Y}$. Hence $\mathrm{F}$ is feebly open

The following result can be proven in a similar way . 


\section{Theorem 4.3}

Let $\mathrm{Go} F: \mathrm{X} \rightarrow \mathrm{Z}$ is feebly open and $\mathrm{F}$ $: \mathrm{X} \rightarrow \mathrm{Y}$ is continuous and surjective, then $\mathrm{G}$ : $\mathrm{Y} \rightarrow \mathrm{Z}$ is feebly open.

\section{Theorem 4.4}

Let $\mathrm{GoF}: \mathrm{X} \rightarrow \mathrm{Z}$ is closed and $\mathrm{G}: \mathrm{Y}$ $\rightarrow Z$ is continuous and injective, then $\mathrm{F}: \mathrm{X} \rightarrow \mathrm{Y}$ is feebly closed.

Proof : Let $H$ be a closed in $X$, to prove $\mathrm{F}(\mathrm{H})$ is feebly closed in $\mathrm{Y}$

Since Go F is closed, then Go $F(H)$ is closed in $\mathrm{Z}$. Since $\mathrm{G}$ is continuous ,then $\mathrm{G}^{-1}(\mathrm{GoF}(\mathrm{H}))$ is closed in $\mathrm{Y}$.

But $G$ is injective , then $\mathrm{G}^{-1}(\mathrm{GoF}(\mathrm{H}))$ $=\mathrm{G}^{-1}(\mathrm{G}(\mathrm{F}(\mathrm{H})))=\mathrm{F}(\mathrm{H})$ is closed in $\mathrm{Y}$, then by Diagram $2.8, \mathrm{~F}(\mathrm{H})$ is feebly closed .Hence $\mathrm{F}$ is feebly closed.

We can easy to prove the following propositions.

\section{Proposition 4.5}

Let $\mathrm{F}: \mathrm{X} \rightarrow \mathrm{Y}$ and $\mathrm{G}: \mathrm{Y} \rightarrow \mathrm{Z}$ be a closed mappings, then GoF: $X \rightarrow Z$ is feebly closed .

\section{Proposition 4.6}

Let $\mathrm{F}: \mathrm{X} \rightarrow \mathrm{Y}$ is closed and $\mathrm{G}: \mathrm{Y} \rightarrow \mathrm{Z}$ is feebly closed, then GoF $: X \rightarrow Z$ is feebly closed.

\section{Proposition 4.7}

Let $\mathrm{GoF}: \mathrm{X} \rightarrow \mathrm{Z}$ is feebly closed and $\mathrm{F}: \mathrm{X} \rightarrow \mathrm{Y}$ is continuous and surjective ,then $\mathrm{G}: \mathrm{Y} \rightarrow \mathrm{Z}$ is feebly closed.

\section{References:}

1. Maheshwari, S.N and Tapi.U.19781979. Note on some applicationsof feebly open sets.Madhya Bharati J.Un. Saugar.

2. Neubrunn, T.1977. A note on mappings of Baire space . Math. Slovaca $27: 173-176$.

3.Kolyada,S. Snoha,L. and Trofimchuk, S.2001. Noninvertible minimal maps,Fund. Math. 168:141163.

4. Mahide Kucuk and Idris Zorlutuna 2000.Aunified theory for weak separation properties, Internat.J.Math. and Math.Sci.24(11):765-772.

5.Dorsett,C.1991.S-separable spaces, feebly continuous functions, and feebly separation axioms.Ganit.11(12):19-24.MR.95a:54036.Zbl818.

\section{2 .}

6.Vella,A.2005.Afundamentally topological on graphtheory.Ph.D. thesis.U.Waterloo. Availableathttp:// etd. uwaterloo.ca/etd/Avella 2005 .pdf.

7.Bonnington ,C.P. and Richter,R.B. 2003. Grapgs embedded in the plane with a bounded number of accumulation points.J.GraphTheory .2(44):132-147.

8. Diestel ,R. and Kuhn,D.2004.On infinite cycles I.Combinatorica (24): 68-89.

9.Ali,K.2003.On semi separations axioms.M.Sc. Thesis. Al-

Mustansiriyah Univ.

10.Levine, N. 1963. Semi open sets and semi-continuity in topological spaces . Amer .Math.Monthly 70: 36-41.

11.Biswas, N. $1970 . \quad$ On characterization of semi -continuous functions .Atti .Accad .Naz .Lincei Rend.Cl.Sci.Fis .Mat. Natzr .(8) 48:399-402.

12. Crossely, S.G. and Hiidebrand S.K.1971.semi -closure, Texas J.Sci:99-112.

13. Devi,R., Maki.H.and Balachandran K.1993.Semi -generalized closed maps and generalized semi closed maps.Mem.Fac.Sci.Kochi

Univ.(Math.)14:41-54.

14.Popa , V.1979. Glasnik Mat.III14 (34): 359-362.

15. Maheshwari, S.N and Jain. P.C .1982 Some new mappings. Mathematica .24 (47) (1-2): 53-55.

16.Jankovic,D.S and Reidly.I.L.1985. On semi separation properties.Indian J.Pure.Appl.Math. 16(9):957-964. 
بعض النتائج حول التطبيقات الضئيلة المفتوحة و الضئيلة المغلقة

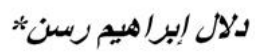

*الجامعة المستتصرية ـكلية التربية ـ قسم الرياضيات.

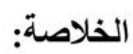

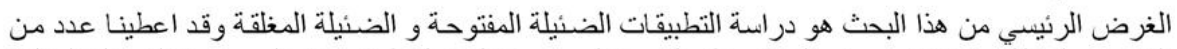

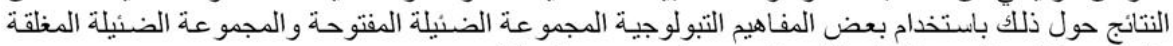

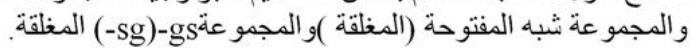

